Journal of Research in Interprofessional

Practice and

Education

Vol. 5.1

March 2015

\title{
Using a Research-Informed Interprofessional Curriculum Framework to Guide Reflection and Future Planning of Interprofessional Education in a Multi-Site Context
}

\author{
Monica Catherine Moran, DSocSc, MPhil OT; Carole Steketee, PhD, \\ B.Ed(Hons), B.Arts(Ed); Dawn Forman, PhD, MBA, PGDip Research; \\ Roger Dunston, PhD, B.A. App. Soc. Stds
}

\begin{abstract}
Background: Over the past two years health educators in Australia have benefited from funding made available from national organizations such as the Office of Learning and Teaching (OLT) and Health Workforce Australia (HWA). Funded research has been conducted into educational activities across the country that aim to promote integrated and sustainable interprofessional learning.

Methods and Findings: A collaboration between multiple stakeholders led to the establishment of a consortium of nine universities and interprofessional organizations. This collaboration resulted in a series of research studies and the development of a conceptual framework to guide the planning and review of interprofessional health curricula. A case study of the development of a suite of health education programs at a regional university in Australia is used to demonstrate how the framework can be used to guide curricular reflection and to plan for the future. Shedding a light on interprofessional health education activities across multiple sites provides a rich picture of current practices and future trends. Commonalities, gaps, and challenges become much more obvious and allow for the development of shared opportunities and solutions.

Conclusions: The production of a shared conceptual framework to facilitate interprofessional curriculum development provides valuable strategies for curricular reflection, review, and forward planning.
\end{abstract}

Keywords: Interprofessional; Conceptual framework; Curriculum; Research

Journal of Research in Interprofessional Practice and Education (JRIPE)

Vol. 5.1

(c) 2015

Corresponding author: Monica Moran. Email:

monica.moran@cqu.edu.au

\section{Introduction}

The importance attached to interprofessional practice (IPP) is now a defining feature of global policy and practice across all areas of health service provision-safety, effectiveness, and sustainability. Despite this global acceptance, the development of interprofessional education (IPE) in support of IPP has been highly problematic, particularly in relation to its conceptual coherence and practical embedding within health professional education curricula. Although there have been a number of signifi- 
2

An IP Curriculum Framework to Retrospectively Review Curriculum

Moran, Steketee, Forman, \& Dunston

Journal of Research in Interprofessional Practice and Education

Vol. 5.1

April 2015 cant attempts to address these issues, until recently progress has been slow, sporadic, and often unsustainable [1,2].

The call for professionals to gain skills that enable collaborative team working is not new. In 1966, the World Health Organization (WHO) stated:

Given that effective healthcare requires the services of personnel with different competencies, it is essential that trainees should have appropriate experience of such cooperative endeavours and have the ability to work towards a common goal, to communicate and share responsibility. [3, p. 28]

The challenge of providing an environment that facilitates students gaining such an experience (termed interprofessional education) has also been well documented [4-6]. A 2010 WHO report [7] reiterated the need for interprofessional education, which is echoed in another WHO from 2013 [8]. Reeves et al. [9] called for more research in this area. Stone [1] insightfully noted that interprofessional learning would not be embedded in health education programs until it became a formal and well-developed part of their curricula, and Soubhi [10] indicated that the rising complexity of patients' needs called for a rising need for collaborative work.

In response to these challenges this article reports on a number of Australian research and development initiatives that have sought to address the above issuescurriculum coherence, development, and embedding. In doing this, we first discuss the design and conduct of three interrelated studies focused on building IPE capacity across the Australian higher education sector. Collectively, the three studies became known as the Curriculum Renewal Studies (CRS) [11] (www.ipehealth.edu.au). In particular, we focus on the design and utilization of an innovative curriculum framework, the "four dimensional curriculum development framework" (4DF) (see Figure 1 and discussion below). The conceptual framing of the 4DF was explicitly designed to generate the kinds of curriculum and pedagogical discussions central to the rationale for and development of IPE as a core component of health professional education curricula. Second, we provide an example of how the $4 \mathrm{DF}$ is being used to review and further develop IPE curricula at one Australian regional university. We have been surprised and pleased at how different individuals and institutions have taken up and utilized the 4DF as a way of thinking about curricula and IPE-friendly curriculum redesign.

The curriculum renewal studies

The three interrelated studies that made up the CRS are:

Interprofessional Education: the National Audit Study (NAS) [6] (www.ipehealth.edu.au)

The NAS developed a national profile of IPE as this was occurring in 26 Australian universities between 2011/12. The NAS was the first study to provide an overview of Australian IPE activity_competencies, learning outcomes, curriculum design, methods of teaching, assessment, evalua- 
An IP Curriculum Framework to Retrospectively Review Curriculum

Moran, Steketee, Forman, \& Dunston

Journal of Research in Interprofessional Practice and Education

Vol. 5.1

April 2015
Journal of Research in Interprofessional Practice and Education

tion, and implementation [11]. The national peak body focused on the development of the Australian health workforce, Health Workforce Australia, funded the NAS.

\section{Interprofessional Education for Health Professionals in Western Australia: Perspectives and Activity (WAS) [12] (www.ipehealth .edu.au)}

This qualitative in-depth study complemented the NAS. It developed a narrative account of IPE curriculum development across four Western Australian universities. As well as documenting the principal IPE activities in depth, the study examined cultural, logistical, and strategic factors that had an impact on the development and delivery of IPE [12]. The WAS was funded by the Western Australian Department of Health.

\section{Curriculum Renewal for Interprofessional Education in Health (CRIEH) [13] (www.ipehealth.edu.au)}

This was the overarching study in the CRS program and operated over the timeline of the NAS and WAS. The CRIEH built on the insights, findings, and networks developed by the other studies to generate IPEspecific curriculum resources that would support and enable the development of Australian IPE [11]. The national peak body focused on education and learning within the higher education sector, the Office for Learning and Teaching (OLT), funded CRIEH.

\section{The curriculum renewal studies: Aims}

The CRS was an ambitious endeavour. It was designed to achieve four aims. Firstly, to develop new understandings about the state of IPE curricula in Australian universities. For example, how it was conceptualized, implemented, assessed, and evaluated. The CRS provided the first national profile of IPE as it existed in Australia in 2011/2012 (The Interprofessional Renewal Consortium, Australia 2013) [13]. Secondly, to generate a range of useful and accessible IPE curriculum resources that would support and enable those involved in health professional education, in particular IPE. Thirdly, to build on, strengthen, and extend existing Australian IPE networks. Finally, the study was also focused on working to influence and enable change.

In developing these ambitious aims, in particular, the aim related to change, we were acutely aware that working to influence and enable change would require far more than simply generating new information about IPE. Rather, it would, as consistently identified in the literature, require the CRS to engage with culture, status, power, history, and the ways in which disciplinary or uni-disciplinary knowledge, education and, practice had become dominant as a way of conceptualizing and delivering health professional education [15].

What follows is an account of how we sought to address this challenge. We discuss the theories and methods we used; in particular, we discuss the development and contribution of the $4 \mathrm{DF}$ within and beyond the scope of the project. 
4

An IP Curriculum Framework to Retrospectively Review Curriculum

Moran, Steketee, Forman, \& Dunston

Journal of Research in Interprofessional Practice and Education

Vol. 5.1

April 2015

\section{Theoretical framing}

Informing the methods design of the CRS were key concepts drawn from a number of socio-material theories, in particular the work of Schatzki et al. [16] and Schatzki [17] - practice theory; LaTour [18] and Law [19] —actor-network theory; Engestrom [20] - cultural historical activity theory, in particular his work on expansive learning; Wenger [21] - with a focus on learning as a social and collective process, in particular the work on communities of practice; and Klein [22] - with a focus on the dominance of uni-disciplinarity and the need for Interdisciplinarity. ${ }^{1}$

The theoretical and conceptual work of the above scholars addressed the interrelated areas of knowledge formation, education, practice, and change. Socio-material theorizations present very different ways of conceptualizing knowledge, education, and practice. For example, socio-material theorists view practice and knowledge as something that is situated in place and time and that is social, collective, negotiated, co-constructed, provisional, dynamic, adaptive, embodied, and embedded-informed by and informing broader social, economic, cultural, and political arrangements [19-21]. Such a view contrasts markedly with the view that currently informs much health professional education, that is, disciplinary theorizations. Disciplinary theorizations emphasize knowledge, practice, and education as occurring within sharply defined, unique, and exclusive knowledge domains and as primarily individual, cognitive, and competency-based achievements [17]. We believe socio-material theorizations have much to offer in building the kinds of knowledge, curricula, and capabilities required by all contemporary health professionals and align strongly with the interprofessional views of knowledge, practice, and learning [23].

\section{Methods}

In keeping with our socio-material framing of knowledge, practice and change, the CRS utilized three interrelated but discrete methods.

First, and central to how we worked in all three studies, was a commitment to active forms of participation. The NAS utilized two primary forms of participationa national survey and a series of targeted key stakeholder consultations. The WAS utilized semi-structured and in-depth interviewing. We were interested in identifying developmental narratives.

Second, our methods work in the CRIEH extended the stakeholder-focused consultations and interviews of the NAS and WAS. Our aim here was to expand and resource conceptualization and discussion. We aimed to generate what cultural historical activity theorists refer to as the conditions for "expansive learning" [24]. In addition to utilizing what had been learned from the NAS and WAS-an Australian perspective-we scanned the literature and utilized the experience of team members and members of the international advisory group to identify national and international models and approaches that were regarded as constituting "good" educational practice. We used this material to invite comment and discussion-often divergent debate. We purposefully avoided identifying a one-size-fits-all solution. 
5

An IP Curriculum Framework to Retrospectively Review Curriculum

Moran, Steketee, Forman, \& Dunston

Although the development of a participatory and iterative approach to discussing the development of IPE came easily, we spent considerable time in discussing how we would focus and structure the consultations, interviews, networks, and eventsthe national conversation - that we had agreed to conduct. What emerged from our discussions within the management team, with our international advisory group, and from our previous literature review activity in the area of IPE curriculum development [24] was the idea of developing and using an expansive curriculum development framework that would allow us to focus attention on curriculum, education,

Figure 1.

\section{The four-dimensional curriculum development framework} (4D Framework)

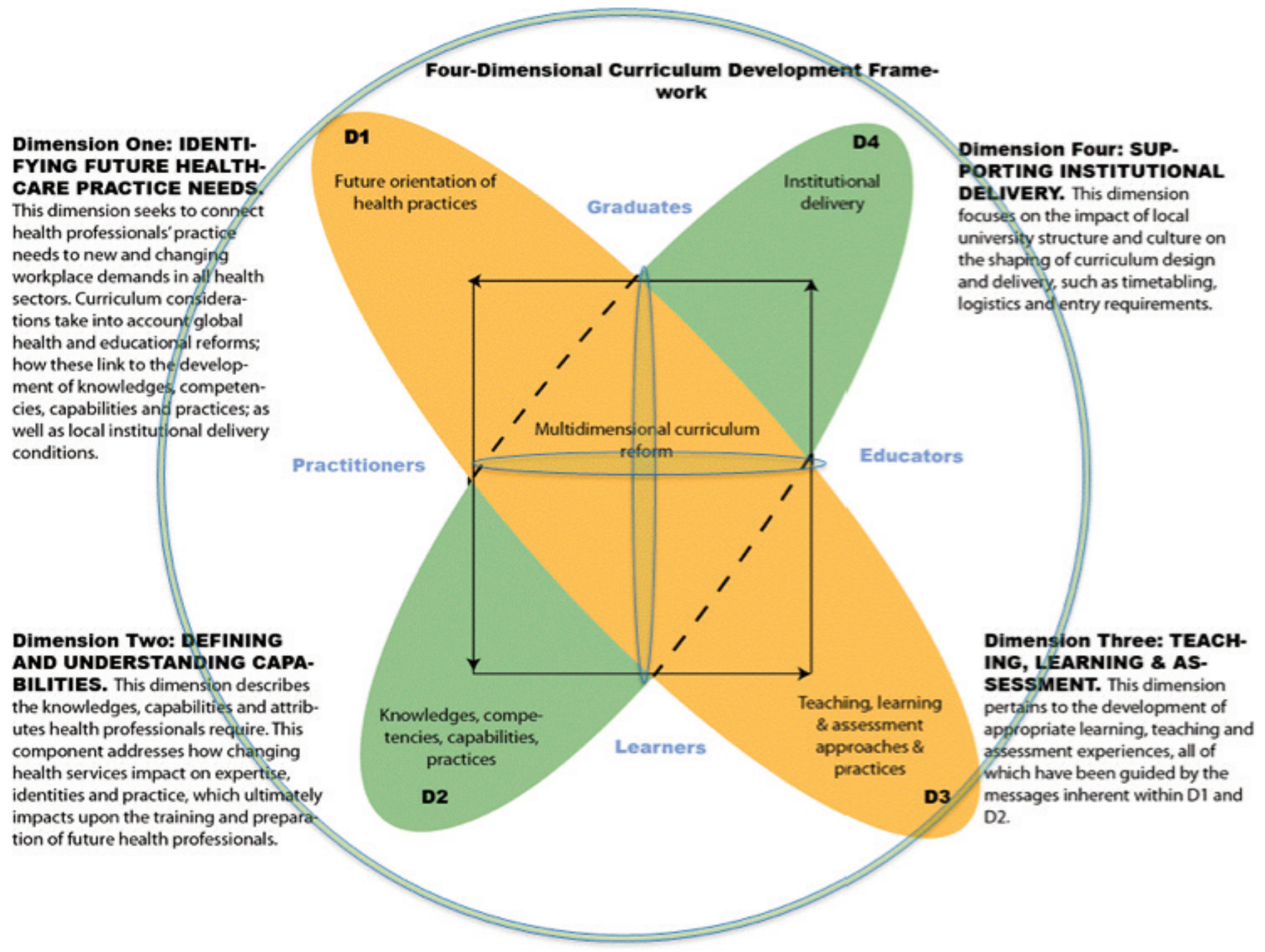

Journal of Research in Interprofessional Practice and Education

Vol. 5.1

April 2015 and practice as social, cultural, and historical achievements, that is, as artefacts as opposed to educational and historical givens. The 4DF became our third methodan artefact that could be used to focus and structure discussion (see Figure 1). Our message here was: "curriculum could be remade." Opening up new ways to think about the nature of practice, education, and curricula would, it seemed to us, be vital for generating a space of exploration and learning. The conceptual framework we 
6

An IP Curriculum Framework to Retrospectively Review Curriculum

Moran, Steketee, Forman, \& Dunston

Journal of Research in Interprofessional Practice and Education

Vol. 5.1

April 2015 developed and utilized to focus, structure, and communicate across all aspects of the work of the CRS was the 4DF.

\section{The 4DF explained}

The $4 \mathrm{DF}$ is a conceptual framework that focuses attention on linkages between curriculum dimensions and bigger-picture issues that impact and shape health professional education, practice, and policy. The four curriculum dimensions are presented as linked to and dependent on one another and in their aggregate and interrelatedness provide a comprehensive picture of the dynamic interplay between curricula elements. Dimension one asks developers to ask "what is this curriculum for?" "What is the professional landscape that it aims to prepare students for, now and in the future?" In answering these questions, the social, political, and economic influences that underpin the profession are taken into consideration and designed into the fabric of a course. Dimension two invites consideration of the specific knowledge, skills, and capabilities that define competency in a particular area. The learning outcomes arrived at in this dimension are necessarily influenced by the assumptions made in dimension one. Dimension three looks at how the curriculum is to be delivered in terms of the teaching, learning, and assessment practices. Elements of the previous two dimensions are considered in determining these practices and how they drive the practicalities associated with the selection and sequencing of learning activities. Dimension four addresses often overlooked aspects of what shapes curricula at the local level, for example, cultural norms and practices, institutional protocols, procedures, and, inevitably, the politics of local institutions. Such factors and the interplay between them frequently shape curriculum in significant ways [25-27].

The 4DF provided us with a way to structure surveys, develop consultations, communicate about the study, and publish our findings. In a final national forum that was funded to bring key stakeholders together across education, health, government, and the professions, the focus and structure of the 4DF was utilized to think through how we would approach the future of IPE. While recognizing the importance of practical programmatic dimensions of curriculum, such as the need to articulate outcomes/competencies and activities, the $4 \mathrm{DF}$ proposes that there are other equally important dimensions-contextual dimensions-that influence the what, why, when, and how of an educational program. Importantly, the articulation of the 4DF also focuses attention on the "big picture" factors that shape how practice, curricula, and education are discussed, for example, the political, social, cultural, and economic issues that shape education, professional identity, status, as well as the significant contextual nuances inherent within the educational institution that influence delivery. 
7

An IP Curriculum Framework to Retrospectively Review Curriculum

Moran, Steketee, Forman, \& Dunston

Journal of Research in Interprofessional Practice and Education

Vol. 5.1

April 2015
Such factors include various health reports on quality, safety and access to healthcare; changing health demographics; the push to specialisation and the demise of general medicine; the reassessment of the role of primary healthcare; the push for greater collaboration among health professions and the changing role of health consumers and communities; and the move to global healthcare and the internationalisation of curricula-all have implications on what counts as curriculum in terms of priorities, funding structures and educational activity. Yet these issues are rarely considered systematically as part of the curriculum design process, being treated by default as somehow sitting outside the educational questions of competencies and outcomes. [7, p. 31]

Developing such an approach aligned well with our previous literature review activity [13], which was that curriculum development was frequently reduced to a focus on dimensions 2 and 3 of the curriculum-learning outcomes, educational methods, and assessment. What was far less developed were models of curricula that made a strong connection to the changing world of practice, dimension 1, and the challenges of building new ways of thinking into local curricula, dimension 4 . Utilizing the $4 \mathrm{DF}$ as a focus and framework for discussion created opportunities for critical reflection and discussion on the relationships between existing disciplinary curricula and what was being required in practice, a greater exposure to and capability in IPP. Additionally, we hoped that by utilizing a framework where curriculum, education, and practice were identified as historical artefacts, we would create a more open and exploratory discussion that would pose new questions about the dominant focus of university health professional education, uni-disciplinarity, and its relationship to an interprofessional approach and pedagogy.

\section{The $4 \mathrm{DF}$ as a framework to guide review and redesign}

The $4 \mathrm{DF}$ was instrumental in framing the findings to emerge from the NAS and in shaping the structure and focus of the CRIEH study. However, its potential, it seemed to us, is greater in that it can be used to guide and inform the development of new health professional curricula. Projects are currently underway within the Consortium ${ }^{2}$ whereby the $4 \mathrm{DF}$ is being used to scaffold the process of IPE design and integration into health professional courses.

It has also become evident that the $4 \mathrm{DF}$ can be used as a reflexive lens to better understand the nuances of existing programs and shed light on the reasons why and how IPE has largely failed to gain traction in mainstream health professional education curricula. The following case study reports the use of the $4 \mathrm{DF}$ in this capacity-as a retrospective lens to analyze the extent to which IPE has been embedded into the first year of a new suite of health professional courses in a regional Australian university. Learnings from this review process will be instrumental in guiding IPE implementation into subsequent years of these programs. The $4 \mathrm{DF}$ provides a structure to guide review, reflection, and evaluation of the cur- 
8

An IP Curriculum Framework to Retrospectively Review Curriculum

Moran, Steketee, Forman, \& Dunston

Journal of Research in Interprofessional Practice and Education

Vol. 5.1

April 2015 riculum development activities that engaged academic staff. Springboarding from this review process, the model provides a roadmap for ongoing development of the subsequent years of the programs.

\section{Case study: Application of the 4DF as a reflexive tool}

In 2011, a regional Australian university proposed the development of a suite of allied health programs including occupational therapy, physiotherapy, podiatry, and speech pathology. Although the university is located in a geographically diverse region of great natural resources, it has historically high levels of social disadvantage and significant health workforce shortage. Coupled with existing socio-economic and health inequities, the region recently underwent rapid changes to the structure of many small towns with an expansion in the resources industry. Although this expansion provided much-needed financial investment, the introduction of large numbers of temporary workers placed significantly increased demands on limited local services. Over many years, the region has struggled to attract and retain health practitioners, and a strong motivation for the introduction of the allied health programs is to reverse this trend by providing local health education opportunities and growing the local health workforce. The proposal for the development of four new allied health programs was seen as an important one for the university and the region.

Early in 2012, a team of academic staff was recruited to establish the four new allied health programs. This team recognized the unique position they were in to build an interprofessional curriculum (or suite of curricula) from the ground up with the possibility of "designing out" many of the barriers to IPE widely published in the literature [1]. An issue that was to prove critical in this design process was the fact that a common first year for all four programs had already been planned within the university. This year comprised foundation learning content for health sciences.

Throughout the past year, the academic team has worked prospectively on the planning of development of the next three years of the professional programs while at the same time observing and reflecting upon the learning experiences offered in first year. The $4 \mathrm{DF}$ provides a wide lens through which to strategically organize and analyze these reflections as well as assisting with the forward planning for the remaining years of the programs.

\section{Dimension one: Identifying future healthcare practice needs}

Although the $4 \mathrm{DF}$ was not used to guide the development process of the first year of the new programs, it is possible to describe early actions carried out by the lead team as those relevant to dimension one of the $4 \mathrm{DF}$. This dimension asks developers to consider the big picture "mission and vision" of a program in terms of why it is important and how it will interact with a range of social, political, economic, and educational factors such as regional/rural location, community expectations, role of the university, and workforce demands.

Through consultation with local health service providers and community stakeholders, the team was abundantly aware of the unique features and needs of the healthcare landscape in the region, and the necessity for the new programs to meet 
9

An IP Curriculum Framework to Retrospectively Review Curriculum

Moran, Steketee, Forman, \& Dunston

Journal of Research in Interprofessional Practice and Education

Vol. 5.1

April 2015 these needs now and into the future. Due to the vast distances between universities, the region is chronically short-staffed of health professionals and recruitment and retention of health professionals is a constant problem. Throughout the area there is a high incidence of chronic diseases, a high percentage of Indigenous residents (almost double the national average), and a mining population suffering from stresses and strains associated with a fly-in-fly-out lifestyle. Community expectations that the university would provide locally trained health professionals able to cope with local demands were well understood by the lead team. Local clinicians described the need for teams able to work cohesively, interprofessionally, and at times use extended scope of practice and role substitution if an individual discipline was not available.

The establishment of ongoing links with a range of key stakeholders facilitated a greater understanding of the big picture in terms of needs for health workforce provision now and into the future. It also provided coalface insight into the experience of communities lacking culturally sensitive team-based health and social care. In order to enhance students' capacities to operate in culturally sensitive practices, links were made with the university's Office of Indigenous Engagement and a commitment was made to "indigenize" the curricula across the programs, both interprofessionally and uni-professionally.

Concurrent with the desire to build more interprofessionally focused programs, the lead team also had to attend to the individual accreditation requirements from each of their professional backgrounds. A starting point for each of the educational leads was the development and articulation of program-wide learning objectives for the individual programs. When mapped they provide the first evidence of the linkages and shared learning goals across the professional programs.

On reflection, the significant pressures to meet national accreditation requirements for new programs took our attention away from the big-picture development of IPE in earlier years. However, the development of teaching spaces has allowed us to create the physical foundations for future IPE. The team planning of a suite of specialist teaching spaces suitable for both uni-professional and interprofessional learning provides us with great latitude in developing future interprofessional teaching and learning opportunities and removes one of the most commonly cited barriers to IPE.

\section{Dimension two: Defining and understanding capabilities}

Dimension two invites consideration of the specific knowledge, skills, and capabilities that define competency in a particular area. Following consultation with practising health professionals across the region, it became apparent that the programs should address context-specific capabilities, as well as industry standards. In particular, the challenges associated with practising in rural and remote settings, such as isolation from professional and peer support, poorly defined career pathways, limited locum availability, and lack of professional recognition [11] flagged the importance of embedding interprofessional competencies in the programs. In order to ensure that this ethos was established from the outset, the team has conducted interprofessional reference groups and participates in program advisory committees for one 
An IP Curriculum Framework to Retrospectively Review Curriculum

Moran, Steketee, Forman, \& Dunston

Journal of Research in Interprofessional

Practice and Education

Vol. 5.1

April 2015 another. More specifically, an interprofessional course focusing on rural and remote health practice has been designed. This course will be rolled out in the third year of study and will draw heavily on the feedback and recommendations of rural health practitioners about the need for interprofessional communication, shared service delivery models, and creative leadership roles within rural teams. Co-ordinating the acquisition of uni-professional competencies along with interprofessional competencies continues to require significant work at the course-planning level.

\section{Dimension three: Teaching, learning, and assessment}

Dimension three looks at how the curriculum is to be delivered in terms of the teaching, learning, and assessment practices. Elements of the previous two dimensions are considered in determining these practices and how they drive the practicalities associated with the selection and sequencing of learning activities. As a common first year of the programs was already developed, it was not initially possible to influence teaching, learning, and assessment practices in the first iteration of this year. However, program leaders are working together to critically review the teaching, learning, and assessment practices across this year to identify opportunities within the existing courses to introduce new interprofessional learning activities and assessments. Concurrently, program leaders are also looking at ways to develop new courses in first year that can be customized with agreed upon interprofessional learning objectives, collaboratively designed interprofessional learning activities, and innovative interprofessional assessment tasks. One example of this is the proposed development of a new Lifespan Development course that will introduce foundation content about lifespan development and then progress to identifying and exploring the roles of various health professions at different phases of the lifespan and how they work together to support optimum human development for their clients/patients.

The lead team has identified that exposing students to interprofessional clinical learning and debrief sessions is paramount for the reality of working together, and this has been embedded in the second, third, and fourth years of the programs' structures. For example, second-year speech pathology (SP) and occupational therapy (OT) students complete an interprofessional learning activity where interprofessional pairs of students spend time in kindergarten settings conducting joint observations of young children. They then attend an interprofessional debrief with an OT and SP tutor where they jointly analyze their observations and practice developing interprofessional intervention plans. Throughout the ongoing process of developing interprofessional teaching and learning activities for the four programs, the input of community-based interprofessional teams cannot be overestimated. They bring rich resources and have been integral in contributing complex interprofessional case materials and clinical teaching opportunities for our students.

\section{Dimension four: Supporting institutional delivery}

Dimension four addresses the often overlooked aspects of the cultural norms, protocols, and procedures inherent within the educational context. Local circumstances such as regional needs, mixture of professions, and institutional priorities influence 
11

An IP Curriculum Framework to Retrospectively Review Curriculum

Moran, Steketee, Forman, \& Dunston

Journal of Research in Interprofessional Practice and Education

Vol. 5.1

April 2015 how curricula can be changed or developed. This regional university with expertise in flexible and distance learning has a strong vision to widen participation in the communities it serves, and $45 \%$ of students are from lower socioeconomic backgrounds. However, the simultaneous development of four new health programs has had an impact on organizational demands. In comparison with distance education programs, the internal programs are highly resource intensive. The need for ongoing budgeting for specialist clinical and teaching spaces and equipment continues to require careful negotiation. This has resulted in the establishment of a suite of shared teaching labs that are available for all the professions to use both in uni- and interprofessional modes. Negotiations for the scheduling of different courses at the same time so that joint teaching and learning activities can occur have proved complex. Also, institutional processes and protocols regarding curriculum development have required ongoing consultation and, at times, compromise. Proposals involving integration of components of differently coded courses so that they can include elements of uni-professional and interprofessional learning have tested existing institutional systems. Negotiations continue on how to make processes more responsive and adaptive to the needs and challenges of curriculum planning at the institutional level.

\section{Discussion}

Development of new interprofessional programs is multi-dimensional. Curriculum development goes far beyond the usual curricular exercises of articulating learning objectives, designing weekly learning activities, and assessing learning outcomes. Relationship building within and beyond the university is vital. New programs are an unknown quantity within the university community and there may be preconceptions about the demands such programs place on an already stretched organization. Fears and preconceptions need to be explored, made explicit, and challenged. Taking time for engagement with external stakeholders and organizations provides the critical knowledge required to inform complex interprofessional curriculum design and establish interprofessional clinical learning opportunities.

The $4 \mathrm{DF}$ has facilitated a nuanced and comprehensive reflection on our progress to date. A challenge in using the framework as a retrospective review mechanism and a prospective planning guide has been the difficulty in the temporal positioning of the 4DF. Curriculum development is extremely dynamic and changing, and activities are constantly swinging from one dimension to another. This is to be expected and is acknowledged in the integrated design of the framework, but the concurrent impact of past events and future planning introduces an additional timeline challenge that is not explicitly accounted for in the 4DF. The explicit identification of time points for superimposing the 4DF on our curriculum development work may facilitate deeper and more explicit understandings of our progress and where gaps in our actions may exist.

\section{Conclusion}

The 4DF was developed through research into current practice, taking into account the international work in this field, but concentrating on the work currently taking 
An IP Curriculum Framework to Retrospectively Review Curriculum

Moran, Steketee, Forman, \& Dunston
Journal of Research in Interprofessional Practice and Education

Vol. 5.1

April 2015 place in Australia. The framework provides a structure and process that can be utilized to assist complex curriculum development. Using the 4DF creates opportunities to identify and prioritize actions, isolate and manage risks, and future-proof interprofessional curricula. This article outlines how the 4DF was used to review and reflect on the development of four health professional programs, including occupational therapy, physiotherapy, podiatry, and speech pathology, at a regional Australian University and to inform the planning of subsequent years of these programs.

As the $4 \mathrm{DF}$ developed from research into current practices it is appropriate to continue to use it to guide reflection and inform the planning of the future years of the programs. A series of action research projects are now being planned that will use the $4 \mathrm{DF}$ to focus and facilitate monitoring, reflection, and implementation in the area of IPE across Australia. The outcomes of these projects will be reported in subsequent papers. We see considerable opportunities for the $4 \mathrm{DF}$ to be utilized across a broad range of curriculum development areas to facilitate review, reflection, learning, and more effective implementation.

\section{Acknowledgement}

The authors acknowledge the contribution of the Interprofessional Curriculum Renewal Consortium, Australia (2014).

\section{Notes}

1. Fenwick \& Nerland [23] provide a useful overview of social-material thinking applied to education, learning, and practice.

2. The CRS team have established what we have called The Interprofessional Curriculum Renewal Consortium, Australia.

\section{References}

1. Stone, J. (2010). Moving interprofessional learning forward through formal assessment. Medical Education, 44, 396-403.

2. Suter, E., Deutschlander, S., \& Lait, J. (2011). Using a complex systems perspective to achieve sustainable healthcare practice change. Journal of Research in Interprofessional Practice and Education, 2(1), 83-99.

3. World Health Organization (WHO) (1966). WHO expert committee on nursing, 5th report. Technical report series No. 347. Geneva: WHO.

4. Wilson, P., \& MacMurray, V.D. (1974). Interdisciplinary education: Lowering the barriers to effective learning. Educational Research, 17(1), 27-33.

5. Lee, A., Steketee, C., Rogers, G., \& Moran, M. (2013). Towards a theoretical framework for curriculum development in health professional education. Focus on Health Professional Education, 14(3), 70-83.

6. The Interprofessional Curriculum Renewal Consortium, Australia (2013). Interprofessional education: a national audit. Report to Health Workforce Australia. Sydney: Centre for Research in Learning and Change, University of Technology Sydney.

7. World Health Organization. (2010). Framework for action on interprofessional education \& collaborative practice. Geneva: World Health Organization.

8. World Health Organization. (2013). Transforming and scaling up health professionals' education and training. World Health Organization Guidelines. Geneva: World Health Organization.

9. Reeves, S., Zwarenstein, M., Goldman, J., Barr, H., Freeth, D., Hammick, M., \& Koppel, I. (2008). Interprofessional education: Effects on professional practice and health care outcomes. The Cochrane Database of Systematic Reviews. Jan 23(1): CD002213.

10. Soubhi, H. (2012). Editorial: Complex care and the need for collaborative brains. Journal of Research in Interprofessional Practice and Education, 2(3), 248-249. 
13

An IP Curriculum Framework to Retrospectively Review Curriculum

Moran, Steketee, Forman, \& Dunston
11. The Interprofessional Curriculum Renewal Consortium, Australia. (2014). Interprofessional education: Curriculum renewal for interprofessional education in health. Canberra: Commonwealth of Australia, Office for Learning and Teaching.

12. Nicol, P. (2013). Interprofessional education for health professionals in Western Australia: Perspectives and activity. Sydney: University of Technology Sydney.

13. The Interprofessional Curriculum Renewal Consortium, Australia. (2014). Interprofessional education: Curriculum renewal for interprofessional education in health. Canberra: Commonwealth of Australia, Office for Learning and Teaching.

14. Learning and Teaching for Interprofessional Practice, Australia (L-TIPP), (2009). Interprofessional health education in Australia: The way forward. Sydney: Learning and Teaching for Interprofessional Practice, Australia, with the University of Sydney, the University of Technology Sydney, and the Australian Learning \& Teaching Council.

15. Dunston, R., Lee, A., Matthews, J., Pockett, R., Thistlethwaite, J., \& White, J. (2009). Interprofessional health education in Australia: The way forward. Sydney: Centre for Research in Learning and Change, University of Technology.

16. Schatzki, T.R., Knorr-Cetina, K., \& von Savigny, E. (Eds). (2001). The practice turn in contemporary theory. London and New York: Routledge.

17. Schatzki, T.R. (2002). The site of the social: A philosophical account of the constitution of social life and change. University Park, Pennsylvania: University of Pennsylvania Press.

18. La Tour, B. (2005). Reassembling the social: An introduction to actor-network-theory. Oxford: Oxford University Press.

19. Law, J. (2004). After method: Mess in social science research. New York: Routledge.

20. Engestrom, Y. (2005). Developmental work research: Expanding activity theory in practice. Berlin: Lehmanns Media.

21. Wenger, E. (1998). Communities of practice: Learning, meaning, and identity. Cambridge: Cambridge University Press.

22. Klein, J.T. (1996). Crossing boundaries: Knowledge, disciplinarities and interdisciplinarities. London: University Press Virginia.

23. Fenwick, T., \& Nerland, M. (Eds). (2014). Reconceptualising professional learning. New York: Routledge.

24. Lee, A., Steketee, C., Rogers, G., \& Moran, M. (2013). Towards a theoretical framework for curriculum development in health professional education. Focus on Health Professional Education, 14(3), 70-83.

25. Lee, A., Dunston, R., \& Fowler, C. (2012). Seeing is believing: An embodied pedagogy of doing partnership in child and family health. In Hager, P., Lee, A., \& Reich, A. (Eds.), Practice, learning and change. (pp. 267-276). London: Springer.

26. Nisbet, G., Lee, A., Kumar, K., Thistlethwaite, J., \& Dunston, R. (2011). Interprofessional health education: A literature review overview of international and Australian developments in interprofessional health education (IPE). Sydney: University of Technology, Sydney.

27. The Interprofessional Curriculum Renewal Consortium, Australia. (2013). Interprofessional education: A national audit report to Health Workforce Australia. Sydney: Centre for Research in Learning and Change, University of Technology Sydney.
Journal of Research in Interprofessional Practice and Education

Vol. 5.1

April 2015 